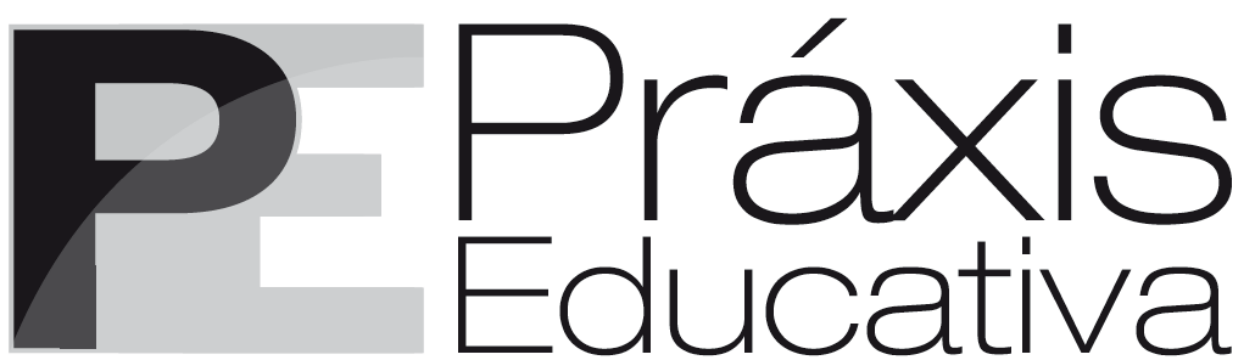

ISSN 1809-4309 (Versão online)

DOI: 10.5212/PraxEduc.v.12i3.009

\title{
Profissão docente e ruralidades contemporâneas: identidade e diferença nas escolas rurais
}

\section{Teaching job and contemporary rural issues: identity and difference in rural schools}

\section{Profesión docente y ruralidades contemporáneas: identidad y diferencia en las escuelas rurales}

\author{
Charles Maycon de Almeida Mota* \\ Fabrício Oliveira da Silva ${ }^{* *}$ \\ Jane Adriana Vasconcelos Pacheco Rios ${ }^{* *}$
}

Resumo: O presente artigo busca compreender de que maneira a profissão docente na roça se reconfigurou diante dos contextos das novas ruralidades e como professores da roça têm considerado as diferenças em suas salas de aula. Tomamos como base teórica as discussões de Moreira (2005), Carneiro $(1998,2012)$, Rios $(2011,2015)$, Pineau (2014) e Silva (2011). Trata-se de uma pesquisa qualitativa em que as narrativas de formação foram o ponto central da investigação. Utilizamos como dispositivos de pesquisa as entrevistas narrativas com três professoras e um professor que moram e exercem a docência na roça, em escolas da rede pública da Educação Básica. Os resultados nos proporcionaram maior entendimento sobre como os sentidos são construídos e ressignificados a partir das novas ruralidades e sua relação com a educação. A conclusão é de que há necessidade da criação de espaços para discussão e formação com ênfase nas questões voltadas para as identidade e as diferenças.

Palavras-chave: Docência. Ruralidades. Diferenças. Pesquisa (auto) biográfica.

Abstract: This article aims at understanding how the teaching job in rural areas has been re-configured in face of the new rural issues and how rural teachers have been addressing differences in their classrooms.

\footnotetext{
* Mestre em Educação e Diversidade pelo Programa de Pós-Graduação em Educação e Diversidade - PPED da Universidade do estado da Bahia - UNEB. Professor da Educação Básica da rede municipal de ensino em Várzea do Poço - BA. Membro do grupo de pesquisa Docência, Narrativas e Diversidade - DIVERSO. E-mail: $<$ charlesmaycon22@hotmail.com>.

** Doutorando em Educação pelo Programa de Pós-Graduação em Educação e Contemporaneidade - PPGEduC da Universidade do Estado da Bahia - UNEB. Mestre em Filologia e Língua Portuguesa pela Universidade de São Paulo - USP. Professor assistente da Universidade do Estado da Bahia, lotado no Departamento de Ciências Humanas e Tecnologias - DCHT - Campus XVI. Membro do grupo de pesquisa Docência, Narrativas e Diversidade DIVERSO. E-mail: <faolis@ig.com.br>.

*** Professora Titular do Programa de Pós-Graduação em Educação e Contemporaneidade - PPGEDUC e do Programa de Pós-Graduação em Educação e Diversidade - PPED - da Universidade do Estado da Bahia - UNEB. Líder do Grupo de Pesquisa Docência, Narrativas e Diversidade - DIVERSO. E-mail: <jhanrios1@yahoo.com.br>.
} 
The theoretical background is based on the discussions proposed by Moreira (2005), Carneiro (1998, 2012), Rios (2011, 2015), Pineau (2014) and Silva (2011). This is a qualitative research in which narratives on education were the focus of investigation. The research tools used were narrative interviews with three female teachers and one male teacher who live and teach in rural environments, in elementary schools belonging to the public education system. The results gave us a better understanding of how meanings are built and re-built from the new rural issues and their relation with education. The conclusion is that there is need for the creation of spaces of discussion and teachers' education emphasizing issues regarding identities and differences.

Keywords: Teaching. Rural Issues. Differences. (Auto) biographical Research.

Resumen: El presente artículo busca comprender de qué manera la profesión docente en el campo se reconfiguró ante los contextos de las nuevas ruralidades y como profesores de la zona rural han considerado las diferencias en sus aulas. La fundamentación teórica sigue a Moreira (2005), Carneiro (1998, 2012), Rios (2011, 2015), Pineau (2014) e Silva (2011). Trata-se de una pesquisa cualitativa en el que las narrativas de formación fue el punto central de la investigación. Utilizamos como dispositivos de investigación las entrevistas narrativas con tres maestras y un profesor que viven y ejercen la docencia en la escuela campesina, en escuelas de la red pública de Educación Básica. Los resultados nos proporcionaron mayor entendimiento sobre cómo los sentidos son construidos y rehechos a partir de las nuevas ruralidades y su relación con la educación. La conclusión es que hay necesidad de crear espacios para discusión y formación con énfasis en las cuestiones dirigidas a las identidades y las diferencias.

Palabras clave: Docencia. Ruralidades. Diferencias. Investigación (auto) biográfica.

\section{Introdução}

Discutir sobre profissão docente em espaços rurais nos provoca a considerar as ruralidades contemporâneas, tendo em vista que esta temática vem ganhando o lugar merecido nos debates sobre as novas identidades em construção, como uma maneira de reposicionamento dos sujeitos que vivem e convivem em territórios rurais. Com isso, a profissão docente vai se constituindo a partir de especificidades destes espaços e das experiências que vão sendo construídas nas relações entre os sujeitos e seus territórios.

Com o rompimento de uma estrutura socioeconômica que entrou em decadência devido aos diversos conflitos sociais e culturais, foram surgindo fissuras que permitiram às minorias políticas invisibilizadas se perceberem como grupo a partir das subjetividades e diferenças que traziam. Isso se desencadeou em torno de uma motivação, promovendo outros olhares para suas próprias realidades de vida. Disso, duas novas condições lhes são produzidas: uma a de mobilizar-se para modificar sua vida e intervir na realidade, a outra de conformar-se com sua vida e ser passivo diante do que a realidade poderia lhe oferecer.

Neste contexto, as escolas rurais foram reconfigurando-se em torno de uma diversidade local e das práticas docentes desenvolvidas nestes espaços. Dessa forma, surge a necessidade de se pensar a respeito das identidades e diferenças no meio escolar, considerando os sentidos e significados que estas produzem na formação dos sujeitos envolvidos. A partir de tais pressupostos, fomos instigados a investigar a profissão docente no espaço rural, enfatizando as seguintes questões: De que maneira a profissão docente na roça se (re)configurou diante das novas ruralidades contemporâneas? Como professores e professoras da roça têm lidado com as diferenças em suas salas de aula?

A fundamentação teórico-metodológica ancorou-se na abordagem (auto)biográfica, entendendo o desenvolvimento da profissão como processo de construção de conhecimento ao 
longo da vida. Essa opção metodológica deveu-se à aproximação da ideia de se compreender como se processam os significados das novas ruralidades contemporâneas, focando na realidade do trabalho docente, buscando analisar como os professores lidam com as diferenças na sala de aula. Neste sentido, tomamos a narrativa como elemento veiculador de sentidos, embasados na epistemologia da (auto)biografia, pois quem narra a própria vida, ao narrar, estabelece relações temporais e de situacionalidade consigo mesmo e com aqueles com quem interage durante o seu percurso profissional. Cria-se aí um espaço biográfico, por meio do qual a narrativa faz emergir os sentidos que os professores atribuem às diferenças, revelando como elas atravessam seu trabalho e como com elas eles lidam.

Como aponta Arfuch (2010), as formas que integram o espaço biográfico apresentam, como característica comum, o fato de que os professores narram, de distintas maneiras, histórias e experiências profissionais que por se constituírem como verdadeiras narrativas estão sujeitas "[...] a certos procedimentos compositivos, entre eles, e prioritariamente, os que remetem ao eixo da temporalidade" (ARFUCH, 2010, p. 111). Ademais, Delory-Momberger (2008, p. 26) considera ser o método (auto)biográfico uma "[...] das formas privilegiadas da atividade mental e reflexiva, segundo a qual o ser humano se apresenta e compreende a si mesmo no seio do seu ambiente social e histórico".

Esse fato é também analisado por Nóvoa e Finger (2014) quando consideram que o método (auto)biográfico dispensa uma atenção particular e especial, além de grande respeito pelos processos de formação das pessoas. Essa, segundo ponderam os referidos pesquisadores, é uma das qualidades que distinguem esse método de outras tantas metodologias aplicadas nas ciências sociais. Isso é considerado pelo grau de respeitabilidade que o método em questão promove ao possibilitar uma longa investigação na compreensão dos processos de formação dos sujeitos que narram suas histórias, produzindo novas histórias e novas formas de se pensar o humano e sua natureza. É nesta direção que Nóvoa e Finger $(2014$, p. 22) afirmam que:

É interessante observar que a introdução do método (auto)biográfico no domínio das ciências da educação não provocou grandes debates teóricos e epistemológicos; menos impregnadas do que as outras ciências sociais por uma perspectiva positivista, as ciências da educação compreenderam de modo algo intuitivo a importância do método (auto)biográfico, que se veio a revelar não apenas um instrumento de investigação mas também, (e sobretudo) um instrumento de formação.

Neste estudo, tomamos a abordagem (auto)biográfica não só como um importante elemento de investigação das compreensões que os professores produzem com o trabalho docente no contexto das ruralidades contemporâneas, mas sobretudo como um instrumento de formação, vez que narrar sobre a profissão e como se lida com ela faz o professor refletir e, consequentemente, inaugurar novas formas de compreender o seu trabalho, bem como os contextos em que ele está inserido. Desta forma, defendemos o princípio de que ao produzir narrativas sobre si e sobre seu trabalho docente, os sujeitos desta pesquisa se inseriram numa condição de reconstruir e de refletir alguns momentos por eles vividos, fazendo aflorar os significados que o ato de narrar é capaz de promover, visto que ele se dá a partir da ideia de que é preciso fazer escolhas sobre o que, quando e como um momento deve ser reconstruído. $\mathrm{O}$ movimento formativo que se pode observar na abordagem (auto)biográfica permite ao sujeito que narra tomar a linguagem como um cenário reflexivo, por meio do qual ele deu forma e sentido às suas experiências com a diversidade na escola, numa condição perene de produção de conhecimento sobre si e sobre o trabalho com as diferenças. 
Tomamos como dispositivo de pesquisa a entrevista narrativa, realizada com três professoras e um professor ${ }^{1}$ que moram e assumem a docência em contextos rurais, no município de Várzea do Poço, situado no Território da Bacia do Jacuípe, no interior da Bahia. Foram critérios para a escolha dos colaboradores da pesquisa a. ser professor de escolas rurais e b. atuar há mais de cinco anos nestas escolas.

A entrevista narrativa se configura na abordagem (auto)biográfica como um dispositivo que nos permite depreender os saberes que um sujeito construiu ao longo de uma trajetória de formação ou até mesmo de vida. Esses saberes poderão servir como forma de orientação para que se possa descrever e analisar os sentidos das experiências que cada professor desenvolveu na docência em contexto rural. A escolha deste dispositivo justifica-se, dentre outros motivos pelo fato de que "[...] através da narrativa, as pessoas lembram o que aconteceu, colocam a experiência em uma sequência, encontram possíveis explicações para isso, e jogam com a cadeia de acontecimentos que constroem a vida individual e social" (JOVCHELOVITCH; BAUER, 2007, p. 91).

A entrevista narrativa favorece ao sujeito a ordenação e sequenciação de suas experiências, buscando explicar os acontecimentos que demarcam suas experiências pessoais na dimensão da vida social. Nessa direção, a escolha deste dispositivo justifica-se na pesquisa por permitir perceber como os sujeitos abordam os sentidos das diferenças e diversidades no contexto rural, tecidos no exercício docente.

$\mathrm{Na}$ abordagem (auto)biográfica, as entrevistas narrativas não se constituem apenas em uma listagem de acontecimentos da vida de um sujeito, como forma de ordenação aleatória de sua trajetória de vida. Para além disso, este dispositivo constitui-se em uma tentativa de relacionar os acontecimentos da vida ao longo das experiências docentes em contextos rurais. Faculta alinhar os acontecimentos de modo a criar um enredo, estruturado por uma concepção de espaço e tempo formativo, que dá sentido às experiências com as diferenças e diversidades no contexto rural, permitindo, assim, o desenvolvimento de uma história que tem começo e fim e que pode sempre ser reconstruída em novo tempo e espaço, logo, produzindo novos sentidos. Trata-se, portanto, de um dispositivo que favorece uma organização dos fatos relevantes da vida dos professores, sobretudo daqueles vivenciados na profissão docente em contextos de ruralidade. Assim, os professores, colaboradores da pesquisa, ao narrarem os fatos reveladores das experiências, organiza-os de forma a potencializar as experiências vividas, apoiando-se na oralidade e na competência reflexiva que a linguagem lhe permite fazer. Souza (2008, p. 91) nos diz que:

As entrevistas narrativas demarcam um espaço onde o sujeito, ao selecionar aspectos da sua existência e tratá-los através da perspectiva oral, organiza suas ideias e potencializa a reconstrução de sua vivência pessoal e profissional de forma auto reflexiva como suporte para a compreensão de sua itinerância vivida [...].

Considerando que um dos objetivos desta pesquisa é compreender como se processam os sentidos das novas ruralidades contemporâneas, focando na realidade do trabalho docente, com o intuito de analisar como os professores lidam com as diferenças na sala de aula, este dispositivo se constituiu em um relevante instrumento que nos permitiu analisar o sentido e a forma como cada um dos professores foram revelando e (re)significando suas experiências na docência em contextos rurais, abordando como a diferença e a diversidade era trabalhada em suas salas. A entrevista narrativa permitiu produzir uma articulação da experiência profissional, produzindo um diálogo entre o individual e o sociocultural, em que os professores foram mobilizando saberes do

\footnotetext{
${ }^{1}$ Os sujeitos da pesquisa serão denominados no decorrer do trabalho com nomes fictícios.
} 
seu arsenal de conhecimentos adquiridos durante a sua lida docente na roça. É nesta seara que se pode abordar a dimensão narração, formação e autoformação, em que as trajetórias formativas revelam as múltiplas redes de relações, as quais identificam as identidades dos sujeitos, bem como a forma como elas vão sendo construídas pelos processos de formação trilhados por cada um durante a formação, bem como durante o desenvolvimento da profissão, no caso da pesquisa em tela, em contextos rurais.

A entrevista narrativa foi utilizada aqui por apresentar um caráter formativo para professores e professoras, possibilitando o processo de autoformação, heteroformação e ecoformação, dimensões adotadas pela teoria tripolar de formação proposta por Pineau (2014). É importante mencionar que tomamos como base de análise dos dados concepções fundamentadas na hermenêutica e fenomenologia, por nos dar condições de compreender e interpretar as narrativas que trazem consigo uma sobrecarga de subjetividades, sentidos e significados da vida de cada sujeito entrevistado. Ao narrarem sobre suas experiências os professores da roça fundamentam suas práticas e vivências a partir das relações que estabelecem consigo, com o outro e com seus espaços de vida.

Discutiremos as novas ruralidades, apresentando as identidades e suas contribuições para se pensar o rural numa dimensão de ressignificação que leva em conta os modos de ser e pensar os territórios rurais, os significados produzidos em detrimento das representações que se fazem destes locais. Na sequência, abordaremos docência na roça e como esta foi sendo produzida nestes contextos a partir do ser e do fazer docente. Por fim, abordaremos a respeito da identidade e diferença como uma maneira de (re)pensar o lugar da diferença nas escolas rurais.

\section{Identidades e ruralidades: uma ressignificação do rural}

As discussões e reflexões acerca das questões que dão centralidade aos sentidos e significados inerentes aos espaços do cotidiano e à produção de nossas vivências e experiências vêm ganhando novas dimensões na contemporaneidade a partir de movimentos que reivindicam outras maneiras de considerar a vida e os lugares em que esta acontece.

Com isso, fomos compreendendo que os modos de viver e pensar os contextos rurais não poderiam estar somente atrelados à produção agrícola que, por sua vez, reservava para o rural um lugar de produção de alimentos e fornecimento de matéria prima, em que, o modo de vida das pessoas da roça ${ }^{2}$ esteve associado a condições de precariedade, escassez, retrocesso, pobreza e atraso social. Essa lógica favoreceu que se tomasse como parâmetros uma visão urbanocêntrica que perpetuava um ideário de que a vida na cidade ofereceria sempre condições de acesso a uma escola de qualidade e, consequentemente, a um mundo civilizado e isento da pobreza e, quando vivenciado, ofereceria às pessoas da roça possibilidades de se libertarem da condição de "não-gente"”.

Esta condição de "não-gente" era reforçada em falas do tipo: "quero que meus filhos estudem na escolas da cidade para ser gente"; "vou morar na cidade para ser gente". Com isso, ressurgia um ideário de que o avançado e progressista se encontrava na cidade e o atrasado e

\footnotetext{
2 Rios (2011, p. 21) concebe roça como uma ruralidade específica, centrada na semiótica da terra, em que, sentidos, itinerários, significados e ressignificações acontecem cotidianamente em caminhos diversos existentes num território configurado por "[...] uma cartografia que passa às margens das roças, que marca passagens, buscas, fronteiras, fazeres de distintas formas".

3 A expressão "não-gente" é considerada aqui a partir das concepções de negação fundamentadas através do processo de imposição de uma condição de superposição que foi se constituindo no imaginário dos excluídos.
}

Práxis Educativa, Ponta Grossa, v. 12, n. 3, p. 848-863, set./dez. 2017 Disponível em: <http://www.revistas2.uepg.br/index.php/praxiseducativa> 
arcaico encontrava-se no campo. Diante de situações como estas, percebemos a proposição de uma visão binária para as relações entre o rural e o urbano, em que, reservava-se para o rural a condição da ausência - um "não-acesso" - e para o urbano as condições da presença e do excesso - um acesso.

Considerando os pressupostos apresentados, compreendemos que acontece um esvaziamento de sentidos dos aspectos culturais e sociais que são produzidos na roça. Isso se evidencia quando não pensamos nas relações estabelecidas nos territórios rurais e por isso desprestigiamos as formas de ser, pensar, fazer e viver em contextos não-urbanos. Tal visão nos faz pensar sob uma ótica da padronização dos processos sociais, econômicos e sociais que se fundamentaram nas ideias de uma identidade fixa e una.

Com fundamentos nas concepções de uma sociedade inspirada no modelo industrial na década de 1970, o filósofo e sociólogo francês Henri Lefebvre (LEFEBVRE, 2002) lança mão de uma teoria que menciona uma completa urbanização. Esta se caracteriza como a suposição da completa urbanização desencadeada por pensamentos vinculados ao desenvolvimento industrial que ocupava as grandes propriedades rurais, suplantando uma ideia de campo, apenas, como um espaço de produção agrícola. Na mesma década temos a suposição de um renascimento rural apresentada pelo geógrafo e sociólogo Bernard Kayser (KAYSER, 1990). No decorrer desses anos, notamos que nenhuma das duas suposições lançadas por tais estudiosos prevaleceram. Assim, podemos inferir que a urbanidade vem engendrar a valorização de uma ruralidade que está nascendo e não renascendo.

Reiteramos que o nascimento de um novo mundo rural supera as condições dos binarismos entre cidade-campo, tradicional-moderno, civilizado-incivilizado, rural-urbano, agrícola-industrial, em que a visão sobre o rural é desqualificada e desvalorizada, reservando, durante muito tempo, para as pessoas que vivem e convivem na roça, uma posição de inferiorização. Neste caso, é emergente a necessidade de concentrarmos esforços na busca de pensar a respeito dos elementos que compõem os princípios que estabelecem relações dinâmicas de interdependências entre os espaços rurais e urbanos. Tais produções são tomadas a partir de concepções desencadeadas com o surgimento das novas ruralidades, que vêm para oferecer sentidos e significados às maneiras de viver e de interagir consigo mesmo, com o outro e com o ambiente em que estão inseridos.

Vale ressaltar que o surgimento de novas ruralidades no Brasil se dá em relação a fatores como: superação de condições de desigualdades sociais e de invisibilidade das minorias políticas existentes; necessidades de construção de um novo mundo rural; necessidade de construção de novas identidades; necessidade de superação de uma visão maniqueísta; necessidade de ressignificação das antigas práticas desenvolvidas no meio rural; participação cidadã e concretização efetiva e real da democracia. Tais fatores se colocam como relevantes por demandarem diversas e diversificadas mobilizações com vistas a outras posturas e posicionamentos que assegurem o respeito e a convivência com as diferenças.

Moreira (2005) apresenta o rural como espaço diversificado e dinâmico, configurado como um espaço utilizado e da vida social. Defende que ruralidade se refere "às relações específicas dos habitantes do campo com a natureza e às relações próprias de interconhecimento destas relações" (MOREIRA, 2005, p. 93). De acordo com esta abordagem, entendemos que o termo "rural" refere-se ao espaço vivido, da experiência e das relações estabelecidas. Já o termo "ruralidade" está reservado para as representações que são construídas a partir das vivências e experiências que acontecem nesses espaços e denotam as maneiras de ver, pensar e viver em contextos rurais. 
Com os movimentos sociais oriundos da pós-modernidade surgiram novas identidades, considerando as subjetividades e as diferenças dos sujeitos, possibilitando a construçãodesconstrução-reconstrução das identidades através dos processos de inter-relações e intersubjetividades. Estes processos desencadeiam momentos de tensões, conflitos e negociações, ocasionando pensamentos que convergem e divergem. Isso provoca a organização de um espaço de diálogo, reposicionando os sujeitos, que por sua vez, revisam e repensam suas concepções a respeito da realidade em que vivem. Desta forma, encontram outros sentidos e significados para viverem e conviverem na roça.

As identidades rurais ressurgem de um espaço que está para além das atividades agrícolas, fundamentadas numa ressignificação do local conectado a outras realidades, sendo estas, rurais e não-rurais, em que a produção cultural é intercambiante e se encontra calcada nas simbologias existentes num cotidiano vivido. Com isso, Carneiro (2012, p. 35) reitera que o rural passa a ser visto como um local de "produção de bens simbólicos que alimenta a indústria cultural e a comunicação entre universos culturais distintos, de origem urbana ou de origem rural".

As ruralidades contemporâneas nos propõem condições para pensarmos numa relação de complementação e interdependência entre o "rural" e o "urbano", superando situações que, em algum momento, tencionaram tais relações num sentido de sobreposição e superioridade. Tais condições fizeram existir fronteiras entre estas duas realidades, ignorando as diferenças e as diversidades dos espaços rurais.

Os elementos presentes no universo da roça contribuem para que as atividades rurais estejam sobrecarregadas de significados, promovedoras de espaços inter-relacionais que fazem ressurgir outras formas de pensar e fazer o cotidiano nestes lugares. Diante de aspectos ligados a estas inter-relações, reiteramos que os contextos rurais adquiriram outras dimensões que superam a visão de um lugar de investimentos agroindustriais, em que, os sujeitos passam a se organizar de maneiras diferenciadas como uma forma de produzir novos sentidos às práticas desenvolvidas em momentos anteriores. Conforme Carneiro (1998, p. 58),

As novas experiências engendradas contribuíram para criar uma diversidade social e cultural que é também condição de existência da sociedade na medida em que alimenta as trocas ao enriquecer os bens (culturais e simbólicos) e ampliar a rede de relações sociais. A heterogeneidade social, ainda que produza uma situação de tensão, não provoca obrigatoriamente a descaracterização da cultura local. Quando aceita pela comunidade, a diversidade assegura a identidade do grupo que experimenta uma consciência de si na relação de alteridade com os "de fora".

É interessante pensarmos numa ruralidade que estabeleça relações com a urbanidade, de modo que, possamos vivenciar os processos de intersubjetividades para a construção de novas identidades. Isso acontece de maneira retroalimentar a partir da troca que provoca um movimento de alteridade, sendo necessário o compartilhamento de saberes e fazeres com o outro. Quando nos propomos a compartilhar bens culturais e simbólicos, estamos nos propondo a estabelecer outras relações que irão nos envolver com os outros, evidenciando condições de pertencimento e não-pertencimento, de identificação e não-identificação permitindo a ampliação de nossas experiências, contribuindo para o enriquecimento de nossas comunidades.

As atividades desenvolvidas no meio rural apresentam especificidades próprias, levando em conta a multiplicidade de sentidos que se encontram embutidas nas relações estabelecidas com os elementos naturais que se colocam nestes lugares. Neste sentido, a produção da vida na roça rompe as estruturas fundamentadas nas lógicas de uma economia centrada nas formas de exploração do ambiente e das pessoas, que estão focadas na produção de outros valores e princípios que se dão a partir das relações de alteridade e com o espaço vivido e inventado. 
Pensar o rural, partindo dos significados que trazem as novas ruralidades, oportuniza-nos compreender tal espaço como um espaço plural e dinâmico capaz de oferecer condições múltiplas de ser e fazer através de possibilidades de ressignificação de práticas e maneiras de produção do cotidiano relacionadas aos modos de viver e de pensar os contextos rurais na contemporaneidade.

Diante disso, é importante enfatizarmos que o conceito de ruralidades contemporâneas se constrói em torno da reconfiguração das identidades das pessoas que vivem e convivem na roça, a partir de uma perspectiva de reinvenção dos diversos modos de relação e inter-relação que estabelecem entre si e com o meio em que se encontram inseridas. Isso as faz produzirem outros sentidos e significados contrários à lógica hegemônica que tenta esvaziar os sentidos das diferenças que estão presentes nos espaços rurais como uma maneira de inferiorização destes espaços e daqueles que são ligados a eles.

As novas ruralidades vão sendo constituídas a partir da produção de bens simbólicos e culturais embutidos nos processos de intersubjetividades que são estabelecidos pelas pessoas da roça que ressignificam suas formas de pensar, viver e agir. Tal situação evidencia uma reconfiguração deste espaço como um local reinventado através de perspectivas de engendramento nas relações com outros espaços, fazendo com que pensemos a docência na roça como um elemento impulsionador dessas relações.

\section{Docência na roça: uma relação entre o ser e o fazer}

A profissão docente tem sido marcada e demarcada por diversas influências de uma sociedade em constantes transformações. Com isso, os fazeres da docência vão sendo construídos a partir do entendimento de que os professores e professoras têm sobre o ser e o fazer, desencadeando a produção de um saber calcado na experiência que associa a formação docente adquirida no decorrer da vida acadêmica com as concepções da realidade vivenciada.

As tessituras da docência no espaço rural engendram sentidos e significados próprios que correlacionam os sujeitos com os elementos naturais dispostos na localidade. Estes, por sua vez, expressam seus modos de viver e pensar de maneira indissociável às relações estabelecidas com tais elementos, produzindo representações e simbologias que possibilitam ressignificações de práticas e vivências de acordo com as alterações de fatores sociais, culturais, econômicos e ambientais.

Cada comunidade rural traz consigo ritmos, rituais, características específicas relacionadas a crenças e a concepções que permeiam estes territórios, podendo permanecer, durante muito tempo, alterados ou não, a depender dos tipos e condições de influência que sofrem ou provocam. As inter-relações e intersubjetividades desenvolvidas nestes espaços estão intimamente relacionadas às formas como as pessoas vivem e interagem com as atividades que precisam desempenhar para que a vida aconteça.

Essa relação de viver e interagir com os outros e com as atividades desempenhadas nos espaços rurais envolve crianças, jovens, adultos e idosos, os co-responsabilizando por suas existências e pela conservação ou não destes espaços. Isso nos permite dizer que a organicidade da vida em contextos rurais atende a uma dinâmica que se encontra condicionada às condições do tempo e espaço da roça. Tais condições, por não serem contempladas pelos currículos escolares das escolas da roça, acabam provocando interrupções na vida estudantil de muitas pessoas que moram na roça, reforçando a ideia de que existe uma grande lacuna entre o espaço escolar e o cotidiano da comunidade. 
Diante desses pressupostos, podemos perceber que a profissão docente tomou, durante muito tempo, um único parâmetro baseado no modelo científico, desvalorizando outros saberes inclusive os oriundos das experiências. Com este cenário, professores e professoras da roça se encontravam numa situação bidirecional, em que, um sentido estava centrado em reproduzir as propostas de um currículo inspirado nas concepções homogeneizadoras e urbanocêntricas. Já o outro sentido se fazia através do reconhecimento das necessidades locais e adaptações aos diversos modos de ser, fazer e viver em meios rurais.

Concebendo que a docência na roça foi sendo construída a partir de situações focadas nas experiências de vida-formação de docentes que inicialmente não se formaram como docentes, mas de acordo às condições de uma determinada época e realidade, foram se constituindo na docência, pelo envolvimento nas atividades culturais e sociais da comunidade, produzindo-a paralelamente a suas obrigações, seus afazeres como agricultores e agricultoras. Essa condição é externada pela narrativa de Renato, que evidencia a transitoriedade de compreensões entre o ser e fazer na docência, na medida em que revela a existência de duas práticas pedagógicas por ele exercidas. Uma em que os aspectos formativos para a docência não estavam presentes e outra que aponta uma visão urbanocêntrica da docência, balizada pelos aspectos formativos que logrou.

\footnotetext{
No ano de 1991, meus pais foram à prefeitura pedir um emprego ao prefeito. Quando eles chegaram em casa me contaram que tinha arrumado um emprego de professor. Eu quase caí de costas, nunca tinha tido formação nenhuma para ensinar. Com oito dias eu tinha que fazer um teste escrito para começar a lecionar. Consegui passar e logo comecei a exercer esta atividade com muita dificuldade por que eu era leigo [...]. Hoje continuo lecionando com uma prática pedagógica completamente diferente daquela do passado, onde o professor transmitia conteúdos sendo uma autoridade entre o saber. Hoje eu tenho que descobrir o que os alunos já têm de conhecimento. Ser um facilitador, um guia para um processo de transmissão de uma série de conhecimento, trabalhar com eles vários tipos de gêneros textuais (RENATO, extrato de narrativa, 2016).
}

Renato vai constituindo-se na docência através de um movimento de autoformação que possibilita uma compreensão de seu papel como professor da roça, demonstrando claramente como realiza seu trabalho docente de acordo com as demandas e necessidades atuais de sua comunidade. Percebemos que este movimento (auto)formativo que Renato apresenta parte da concepção apresentada por Pineau (2014) que se refere ao processo de formação mobilizado a partir da apropriação que o sujeito faz de si mesmo, determinando-se como autorreferencial no espaço formativo que este constitui no decurso da vida. Neste contexto, a compreensão de si e de seu processo formativo tem como um ponto de referência os saberes da experiência.

Esta apropriação de poder de formação que o sujeito articula para formar-se estabelece ligações diretas e dependentes com as perspectivas da heteroformação (ação e interação com os outros) e da ecoformação (ação e interação com o ambiente em que se encontra inserido). De acordo com Pineau (2014, p. 97) "[...] Os desenvolvimentos são produtos das interações entre as pessoas, o meio ambiente e a relação entre os dois, e se fazem por sequências, etapas ou ciclos".

A docência na roça possibilita uma formação articulada a tempos e movimentos instigadores de um processo alimentado pelas inter-relações que se dão nos interstícios gerados por conflitos, tensões, negociações, estranhamentos, diálogos, valorização e reconhecimento no âmbito das localidades em que as escolas estão situadas. Podemos tomar aqui como conflitos, tensões e estranhamentos o encontro das diferenças que cada sujeito traz e expõe no cotidiano escolar, evidenciando posicionamentos e atitudes distintas a respeito de pensamentos reforçados por uma cultura machista, heterossexual, branca e de uma suposta normalidade. Isso fica claro quando na divisão de grupos para brincadeiras algum aluno se recusa a pegar na mão do outro

Práxis Educativa, Ponta Grossa, v. 12, n. 3, p. 848-863, set./dez. 2017 Disponível em: <http://www.revistas2.uepg.br/index.php/praxiseducativa > 
por ele ser negro, meninos não podem brincar com as mesmas brincadeiras das meninas, $\mathrm{o}$ isolamento de alunos deficientes por julgarem-no indefesos ou inferiores. Nestes contextos acontecem também os momentos de negociações, diálogo e valorização intermediados pelos professores ou não.

Essas situações são frequentes e vão se tornando complexas, requerendo que os professores busquem formação e apoio da comunidade para intermediarem os conflitos decorrentes de tais situações. Neste sentido, a concepção da docência para Rafaela encontra-se condicionada a uma busca de formação e a um movimento de alteridade que vai sendo desvelado a partir da interação com a comunidade.

\begin{abstract}
Por ser uma educadora, quero continuar sempre adquirindo mais e mais conhecimento, mesmo que me assombre com o muito que há para aprender. Estudar me faz pensar e desejar. Ao pensar, faço uma leitura de mundo e ao desejar me humanizo, valorizando minhas emoções e as energias que me impulsionam. Todo aprendizado ainda é pouco. [...] Ser professor(a) não é tarefa fácil. Ainda que o professor(a) faça valer sua missão através do seu trabalho e de sua dedicação, se decepciona pela falta da presença e da participação de alguns pais. [...] A minha relação com a comunidade é muito boa. A minha escola é aberta à comunidade. Estou sempre ouvindo e chamando a assumirmos juntos a responsabilidade de transformar a educação da nossa escola (RAFAELA, extrato de narrativa, 2016).
\end{abstract}

A docência na roça vai sendo configurada na valorização das relações estabelecidas entre professores e professoras com suas comunidades engendrando tensões, conflitos, decepções, reconhecimento, valorização e satisfação da realização de uma atividade que requer inteireza e acontece de maneira intensa em nossas vidas. Neste caso, Hall (2003, p. 38) coloca que "a identidade surge não tanto da plenitude da identidade que já está dentro de nós como indivíduos, mas de uma falta de inteireza que é 'preenchida' a partir de nosso exterior, pelas formas através das quais nós imaginamos ser vistos por outros" (grifos do autor).

Neste sentido, podemos considerar que a profissão docente na roça vai se reconfigurando a partir de um movimento que envolve as identidades e subjetividades daqueles e daquelas que a produzem. Conforme Rios (2015, p. 41),

[...] as identidades ocupam um lugar significativo no trabalho docente na roça, uma vez que elas são definidas pela diferença. Considerando que as identidades docentes são construídas através de práticas discursivas, sociais e culturais, definidas pela diversidade que compõe os diversos espaços e tempos de formação dos(as) docentes.

Analisando as compreensões que cada sujeito colaborador da pesquisam desvela em suas narrativas, compreendemos que a profissão docente na roça foi sendo produzida a partir de uma multiplicidade de elementos inerentes às diversidades dos contextos rurais, às identificações e não-identificações, às várias maneiras de pertencimento e não-pertencimento. Neste caso, a entrada na profissão nos espaços rurais atendia a situações específicas e peculiares de cada região, como uma maneira de atender às populações situadas nestes espaços.

No entanto, observamos que há elementos marcados pela subjetividade de cada professor, revelando os sentidos que cada um tem sobre a profissão. Isso é evidenciado pelas concepções que Rafaela constrói em torno da docência. Elas encontram-se baseadas no exercício da profissão docente como uma missão, um sacerdócio, marcando esta construção ao caracterizar a docência como um lugar de encontros e desencontros, frustrações e enaltecimentos que requer dedicação e envolvimento com seus pares.

As tessituras da docência na roça são marcadas por muitas caracterizações, que transversalizam os sentidos que cada professor atribui a si e às condições de desenvolvimento da 
profissão. Vimos, no excerto da narrativa de Marta, como as marcas da invisibilidade são por ela tecidas no reconhecimento de ter sido uma professora leiga.

Foram 20 anos como professora leiga, nome dado a quem não tinha o magistério. Confesso que daí em diante se deu uma trajetória que passei por humilhações diversas. Muitas vezes sentia uma tristeza tão grande em perceber que era "invisível" aos olhos de muitas pessoas de quem tanto queria apoio. [...] O tempo passa e vou em busca de não desanimar. Retornei aos estudos e aos poucos fui recuperando a autoestima. [...] Hoje posso afirmar que as situações de constrangimento a que fui submetida nas diferentes situações pela qual passei no decorrer da vivência como aluna/professora contribuiu para me manter firme, acreditando que os "conflitos" existem e nos resta ter sabedoria para superá-los (MARTA, extrato de narrativa, 2016).

Professores e professoras da roça vão construindo-desconstruindo-reconstruindo suas identidades no decorrer da vida, encontrando mecanismos que os ajudem na superação das dificuldades e elevação de sua autoestima para lidar com as situações diversas que a profissão docente propõe. Neste movimento, o sujeito reinventa-se, transforma-se a partir dos conflitos, pois mobiliza elementos do vir-a-ser inspirados na posição de um sujeito em devir.

A profissão docente na roça ganha dimensões outras quando no referimos às ruralidades contemporâneas, uma vez que, estas se encontram sobrecarregadas de sentidos e simbologias por (re)significar o rural e o reposicionar como um espaço diverso e plural que busca na urbanidade uma relação de interdependência e complementaridade. Neste sentido as ruralidades contemporâneas se projetam como novas representações e condições do ser e do fazer docente. O espaço rural é reinventado e ganha novos sentidos e contornos por ter introjetado situações, condições e representações de uma docência que se representa nos modelos urbanocêntricos. Isso não quer dizer que a roça é um local menor em se considerando as condições e caracterizações sociais, mas é um lugar diferente, que a cada dia se reconfigura em sentidos e experiências pelo modelo urbano. Ser docente na roça significa inserir-se em uma nova ruralidade, a que aqui chamamos de contemporânea por também entendermos que a roça se moderniza ao seu jeito e revela em si novas compreensões sobre o rural e, logo, sobre a docência neste espaço.

Com isso, compreendemos que os sentidos e os significados existentes no espaço da roça exercem de maneira significativa condições diversas nas relações que estabelecemos conosco, com os outros e com o mundo. Assim, o fazer docente nestes espaços se reconfigura de acordo ao processo de reconstrução e reposicionamento dos modos de viver e pensar o rural, compreendendo como eixo central as inter-relações e intersubjetividades que resultam do movimento de alteridade a que somos convidados cotidianamente a realizamos.

\section{$(\mathrm{Re})$ pensando o lugar das diferenças nas escolas rurais}

O cenário educacional tem se mostrado, cada vez mais, como um contexto de encontro cultural que forçosamente impulsiona professores, professoras, gestores e gestoras a repensarem suas práticas a partir de outras perspectivas que possibilitem, não somente validação do conhecimento concebido cientificamente, mas também a valorização de elementos intrínsecos às questões constituintes de concepções pautadas na diferença como responsáveis pela produção de nossas subjetivações e construção-desconstrução-reconstrução de nossas identidades.

Pensar nas questões relacionadas às diferenças nos remete a pensar nas questões referentes às identidades, pois são os elementos da diferença os responsáveis pela produção das identidades através dos processos de inter-relações e intersubjetividades. Neste sentido, 
identidade e diferença estão imbricadas por manterem uma relação de interdependência, marcando e demarcando as condições de ser, pensar e existir dos sujeitos.

Ester atribui as diferenças de comportamento trazidas por seus alunos e alunas à convivência com seus pais, reiterando que seu fazer em sala de aula está baseado na orientação para o bom relacionamento de um aluno ou aluna com o outro, valorizando os princípios do respeito, amor e união.

Procuro observar o comportamento entre eles, estou sempre orientando que devemos respeitar o outro que ninguém é igual, mas somos todos filho de Deus. Cada um com o seu jeito de ser. Procuro trabalhar estas palavras amor, respeito e união. Trago sempre presente as famílias de cada um. Procuro descobrir a convivência familiar para poder entender tal comportamento, se os pais não respeitam as pessoas, provavelmente o filho também vai fazer o mesmo por ser o que apendeu em casa (ESTER, extrato de narrativa, 2016).

A identidade e a diferença, ao longo dos tempos, foram tomadas a partir de uma suposição de pertencimento e não-pertencimento, sendo referenciado para a identidade tudo aquilo que se colocava como bom, puro, divino, já para a diferença estava relacionado ao impuro, ruim, inferior, negativo. Logo, "a identidade e a diferença se traduzem, assim, em declarações sobre quem pertence e sobre quem não pertence, sobre quem está incluído e quem está excluído. Afirmar a identidade significa demarcar fronteiras, significa fazer distinções entre o que fica dentro e o que fica fora" (SILVA, 2011, p. 82).

Pressupostos como estes desencadeiam condições de preconceito e estereótipos a grupos e sujeitos que não estavam incluídos por apresentarem as marcas da diferença de maneira enfática e performática. Isso resultou em diversas situações que tencionaram rompimentos estruturais a partir de movimentos e mobilizações de reivindicação da identidade, considerando fatores relacionados aos conflitos sociais intensificados na contemporaneidade; debates no campo das discussões pós-coloniais; superação da concepção de uma identidade una e fixa; fortalecimento de grupos constituídos pelas minorias políticas; rompimento das macroestruturas.

Todos esses fatores ressurgem dos encontros das subjetividades inerentes à intersecção das diferenças ${ }^{4}$. Isso nos remete a pensar na diferença como um ponto de intercruzamentos de outros diversos pontos que possibilitam a inter-relação e reconstrução de outras diversas conexões responsáveis pela manutenção de elementos que nos tornam sujeitos da individuação, bem como, da coletividade, fazendo com que, não tomemos as diferenças como sinônimo de desigualdade.

Os contextos de nossas escolas encontram-se permeados por maneiras distintas de pensar, ver e saber, em que os sujeitos expõem seus vários jeitos de ser, reagir e interagir com seus pares, culminando em situações de compreensão, conflito, tensão, concordâncias e discordâncias, desencadeando processos de negociações e diálogos, muitas vezes, invisíveis para as formatações curriculares e distantes das posturas utilizadas diante do que foge aos padrões normatizadores, homogeneizantes e condicionantes tomados pela instituição escolar ao longo dos tempos.

Neste sentido, as escolas rurais em suas especificidades se apresentam como um espaço em que se dá o encontro de culturas, em que, as diversidades expelem-se de maneira expansiva requerendo condições outras de visibilidade e posicionamentos que lancem mão de posturas que

\footnotetext{
4 A intersecção das diferenças é tomada neste trabalho como uma maneira de explicitar como os sujeitos são compostos pelas diferenças, em que, a intersecção indica o intercruzamento de linhas num determinado ponto, enquanto a desigualdade se coloca como a separação, aquilo que não pode se encontrar.
}

Práxis Educativa, Ponta Grossa, v. 12, n. 3, p. 848-863, set./dez. 2017 Disponível em: < http://www.revistas2.uepg.br/index.php/praxiseducativa > 
impliquem no desenvolvimento de práticas docentes que tomem como eixo norteador a realidade local e os saberes inerentes aos espaços da roça como forma impulsionadora de aprendizagens, na qual, os sentidos e significados construídos nestes espaços direcionem as propostas pedagógicas dessas escolas. Partindo dos princípios de que a formação dos sujeitos esteja direcionada no sentido da reciprocidade, criam-se maneiras de coexistências entre estes sujeitos e suas localidades. Como reitera Larrosa (2011, p. 45):

Uma cultura inclui os dispositivos para formação de seus membros como sujeitos ou, no sentido que vimos dando até aqui à palavra "sujeito", como seres dotados de certas modalidades de experiência de si. Em qualquer caso, é como se a educação, além de construir e transmitir uma experiência "objetiva" do mundo exterior, construísse e transmitisse também a experiência que as pessoas têm de si mesmas e dos outros como "sujeitos".

Aqui, colocamos a experiência de si como fator intimamente relacionado ao processo educacional como uma prática social que evidencia as mobilizações que os sujeitos fazem de suas experiências e das experiências dos outros, aprendendo e apreendendo a partir da necessidade que temos de construir e transmitir experiências. Então, tais experiências se deslocam no sentido de valorização da vida e dos lugares em que estas são produzidas, bem como, dos sentidos, representações e significados emanados destas produções.

A escola como um território da diferença requer um fazer docente que dê centralidade para as questões referentes à identidade e diferença, como uma proposição de superação de posicionamentos fundamentados numa visão maniqueísta, trazendo possibilidades de construçãodesconstrução-reconstrução das identidades como uma forma de evitar alguns movimentos inspirados na sobreposição cultural que, na maioria das vezes, desconsideram os sujeitos, suas identidades e subjetividades, intensificando processos de exclusão e marginalização.

Podemos contemplar através das narrativas de Rafaela como as diferenças aparecem no cotidiano escolar dos espaços rurais e como a docente concebe a diferença em sala de aula e quais são suas práticas diante deste contexto.

Estou sempre buscando novas práticas que contribui sempre para o desenvolvimento
cognitivo do discente. [...] brincadeiras com carros e bonecas, desenvolvem habilidades
[...] na construção do conhecimento, na maioria dos alunos envolvidos, produzem
mudanças significativas de posturas, amenizando as desigualdades de gênero. São
muitos conflitos como, mulher não joga bola, homem não brinca com menina, na hora
do lanche a cor rosa do prato, do copo e dos talheres é das meninas, a cor azul é do
homem, só as meninas podem ajudar a mamãe em casa, quando o menino cai não pode
chorar, porque homem não chora, etc. Contar história para trabalhar o imaginário do
aluno. Falar que os personagens de princesa e príncipe podem ser negros(as) e
brancos(as) (RAFAELA, extrato de narrativa, 2016).

Professores e professoras da roça vão delineando seus fazeres a partir das buscas de elementos que contribuam no processo pedagógico em sala de aula e possam oferecer possibilidades para o desenvolvimento de um trabalho que seja interventivo. Assim, a postura de Rafaela se apresenta como intermediadora das situações de conflitos que ressurgem em torno do binarismo construído ao longo dos anos, que estabelece fronteiras em decorrência de um modelo social baseado no machismo, na heterossexualidade, nos padrões eurocêntricos. Sendo assim, a professora compreende a necessidade de promover práticas docentes que estejam pautadas em outras lógicas, concebendo como importante uma formação que possa romper com as estruturas que reforçam a inferiorização de um em detrimento da supervalorização do outro e a sobreposição cultural. 
Logo, (re)pensar o lugar das diferenças nas escolas rurais requer que compreendamos a necessidade do rompimento de fronteiras existentes nos espaços escolares e consideremos a riqueza do encontro de culturas que acontece nestes, tomando como pressupostos norteadores práticas que tragam as diferenças para o centro das salas de aula como uma maneira de valorização das experiências de si e das experiências do outro. Isso faz reforçar os princípios da reciprocidade e da coexistência entre os sujeitos como condição de viver e conviver na e com as diversidades.

\section{Considerações}

O estudo evidenciou que as práticas educativas desenvolvidas por docentes em escolas rurais foram reconfigurando-se em torno de uma diversidade local, considerando os modos como cada docente lida com a diversidade; às vezes ratificando e segregando as concepções de diferença. Isso apareceu nas análises das narrativas, dado que os docentes mostram que a prática educativa desenvolvida nas escolas rurais tem a ver com a formação e concepção sobre diversidade que desenvolveram em sua trajetória de vida. Dessa forma, e a partir do que emergiu nas análises, ficou evidente a necessidade de se pensar a respeito das identidades e diferenças no meio escolar, considerando os sentidos e significados que estas produzem na formação dos sujeitos envolvidos, de modo que o docente possa inserir-se numa compreensão de que a prática docente deva sempre ser contextualizada às demandas locais, logo, às novas concepções de práticas educativas em que as diversidades sejam tratadas em sua essência, ao se valorar cada sujeito em sua diferença.

As narrativas revelaram que existe uma caracterização da docência no espaço rural, permeada de sentidos e significados próprios que correlacionam os sujeitos com os elementos e relações naturais que existem na localidade. Os professores trazem à baila seus modos de viverem e de pensarem às relações estabelecidas com contextos da localidade, produzindo representações e simbologias ressignificadoras de experiências que se originam a partir das alterações de fatores sociais, culturais, econômicos e ambientais.

Como fomos percebendo, ao longo das discussões, a profissão docente foi ganhando outros sentidos desencadeados através dos movimentos relacionados ao ser e ao fazer de professores e professoras da roça. Neste caso, a experiência passa a ser um dos elementos principais na produção da docência na roça, pois evidencia outras perspectivas que são responsáveis pela construção-desconstrução-reconstrução das identidades e subjetividades intrínsecas ao processo de inter-relação que traz os requisitos para um fazer docente fundamentado nos princípios da reciprocidade e coexistência entre os sujeitos.

Dessa forma, a profissão docente na roça foi se reconfigurando em detrimento do surgimento das novas ruralidades por considerar as necessidades e demandas de um processo educacional que pudesse atender e atingir às especificidades do local como forma de valorização da vida nos contextos rurais. Tais condições deram visibilidade aos modos de pensar, ver e viver na roça, garantindo a existência de outro lugar para o interconhecimento produzido a partir das relações intersubjetivas entre os sujeitos e o ambiente em que estão inseridos.

Vimos que em torno da docência imperam aspectos formativos que apontam uma visão urbanocêntrica da docência, balizada pelos sentidos que se atribui ainda às práticas educativas na escola rural, mas já reconhecendo que existe uma nova compreensão de ruralidade contemporânea, que torna o rural, não menor que o urbano, mas diferente, com sua singularidade e originalidade. Essa condição tem a ver com uma visão que se evidenciou na pesquisa, que concebe a docência na roça constituída a partir de uma formação articulada a tempos e 
movimentos formativos alimentados pelas inter-relações que se dão nos interstícios gerados por conflitos, tensões, negociações, estranhamentos, diálogos, valorização e reconhecimento dos sujeitos que estão nas escolas rurais, e que fazem dela um espaço de produção de experiências em que a ruralidade é tecida numa nova compreensão do espaço rural e de sua dinâmica organizacional.

Neste sentido, o trabalho concluiu que a docência na roça foi sendo configurada na valorização das relações estabelecidas entre professores e professoras com suas comunidades engendrando tensões, conflitos, decepções, reconhecimento, valorização e satisfação da realização de uma atividade que requer inteireza e acontece de maneira intensa na vida e prática educativa dos professores. É nesta perspectiva que professores e professoras da roça vão construindo-desconstruindo-reconstruindo suas identidades no decorrer da vida, encontrando modos de fazer a docência, buscando valorar sua autoestima e autonomia para lidar com situações que a profissão propicia, sobretudo no contexto em que se pretende trabalhar com a diversidade. É nesse cenário que as ruralidades, no estudo analisadas como contemporâneas, configuram-se como novas representações da condição do fazer docente no espaço rural, que passa a ser inventado e ganha novos sentidos e contornos.

Partindo desse pressuposto, cabe ressaltar que as diferenças em sala de aula são concebidas por professoras e professores da roça de maneiras diversas. Essa análise nos fez perceber que, ainda, existem resquícios de um pensamento que atrela a diferença a um caráter do que precisa melhorar ou se adequar. Isso nos remete a pensar que os espaços escolares encontram-se permeados por forças padronizadoras que impõem uma ideologia que favorece aos sentidos de esvaziamento do real significado da diferença. Mesmo com estes ranços ideológicos existentes no interior das escolas há professores e professoras desenvolvendo práticas docentes que valorizam a maneira de ser de alunos e alunas e buscam, à sua maneira, intermediar os processos de conflitos, tensões e negociações inerentes ao encontro da cultura na escola.

Diante disso, é necessário criar espaços de discussões e formação que levem em conta os contextos de diversidades em nossas escolas, dando um enfoque às questões da identidade e diferença como elementos preponderantes para o respeito, compreensão e conhecimento de si, este, por sua vez, engloba o nós, os outros e o ambiente que nos cerca.

\section{Referências}

ARFUCH, L. O espaço biográfico: dilemas da subjetividade contemporânea. Tradução de Paloma Vidal. Rio de Janeiro: EdUERJ, 2010.

DELORY-MOMBERGER, C. Biografia e educação: figuras do indivíduo-projeto. São Paulo: PAULUS, 2008.

CARNEIRO, M. J. Ruralidades: novas identidades em construção. Estudos Sociedade e Agricultura, Rio de Janeiro, n. 11, p. 53-75. out. 1998.

CARNEIRO, M. J. Do "rural" como categoria de pensamento e como categoria analítica. In: CARNEIRO, M. J. Ruralidades contemporâneas: modos de viver e pensar o rural na sociedade brasileira. Rio de Janeiro: Mauad, 2012. p. 23-50.

HALL, S. A identidade cultural na pós-modernidade. 8. ed. Rio de Janeiro: DP\&A, 2003. 
JOVCHELOVITCH, S.; BAUER, M. W. Entrevista narrativa. In: BAUER, M. W.; GASKELL, G. Pesquisa qualitativa com texto, imagem e som: um manual prático. Tradução de Pedrinho Guareschi. 6. ed. Petrópolis: Vozes, 2007, p. 90-113.

KAYSER, B. La renaissance rurale: sociologie des campagnes du monde occidental. Paris: Armand Colin, 1990.

LARROSA, J. Tecnologias do eu e educação. In: SILVA, T. T. (Org.). O sujeito da educação: estudos foucautianos. 8 ed. Petropólis: Vozes, 2011. p. 35-86.

LEFEBVRE, H. A revolução urbana. Belo Horizonte: Editora UFMG, 2002.

MOREIRA, R. J. (Org.). Identidades sociais: ruralidades no Brasil contemporâneo. Rio de Janeiro: DP\&A, 2005.

NÓVOA, A.; FINGER, M. (Orgs.). O método (auto) biográfico e a formação. São Paulo: Paulus, 2014.

PINEAU, G. A autoformação no decurso da vida: entre a hetero e a autoformação. In: FINGER, M.; NÓVOA, A. (Org.). O método (auto)biográfico e a formação. 2. ed. Natal: EDUFRN, 2014. p. 91-110.

RIOS, J. A. V. P. Ser ou não ser da roça, eis a questão! Identidades e discursos na escola. Salvador: EDUFBA, 2011.

RIOS, J. A. V. P. Profissão docente na roça. Salvador: EDUFBA, 2015.

SILVA, T. T. Identidade e Diferença: A perspectiva dos Estudos Culturais. 10. ed. Petrópolis: Vozes, 2011.

SOUZA, E. C. Histórias de vida, escritas de si e abordagem experiencial. In: SOUZA, E. C.; MIGNOT, A. C. V. (Org.). Histórias de vida e formação de professores. Rio de Janeiro: Quartet, 2008. p. 89-98.

VEIGA, J. E. Destinos da ruralidade no processo de globalização. Estudos avançados, São Paulo, v. 18, n. 51, p. 51-67, maio/ago. 2004. DOI: 10.1590/s0103-40142004000200003

Recebido em 03/11/2016

Versão corrigida recebida em 05/06/2017

Aceito em 08/06/2017

Publicado na versão online em 07/07/2017 